\title{
Rekomendasi Perancangan Arsitektur Enterprise Pascamerger (Studi kasus: Universitas Telkom)
}

\author{
Indra Lukmana Sardi ${ }^{\# 1}$, Kridanto Surendro ${ }^{* 2}$ \\ \# Fakultas Informatika, Telkom University \\ Jl. Telekomunikasi Bandung Indonesia \\ ${ }^{1}$ indraluk@telkomuniversity.ac.id \\ ${ }^{*}$ Sekolah Teknik Elektro dan Informatika, Institut Teknologi Bandung \\ JL. Ganesha 10 Bandung Indonesia \\ ${ }^{2}$ surendro@gmail.com
}

\begin{abstract}
Merger is the combining of two or more companies to form one company including acquisition and other forms of merger. Merger process has many challenges in post-merger integration (Trautwein, 1990). The integration process can trigger many problems and changes. A bad integration can cause failure in merger process completely (Shrivastava, 1986). This research tried to analyze and formulate the recommendation of enterprise architecture design which can overcome those potential problems in integration stage post-merger process. It is hoped by having a good enterprise architecture design it will create the suitability between information technology and business needs. By using the approach of IT governance and TOGAF ADM, it was designed the stages of enterprise architecture consisting of Phase A Vision Architecture, Phase B Business Architecture, Phase C Information System Architecture, Phase D Technology Architecture, and Phase E Opportunity and Solution. Finally, this research can result steps and potential problems need to be paid attention post-merger process in a university.Those steps were measured and compared to the merging prosesses of Telkom University. As a result, the recommendations of enterprise architecture design in post-merger is align with the university's needs.
\end{abstract}

Keywords: Merger, University, Enterprise Architecture, Togaf ADM, SAW Multicriteria Decission Making

\section{Abstrak}

Merger merupakan kombinasi dari dua atau lebih perusahaan menjadi sebuah perusahaan tunggal yang mencakup akuisi serta bentuk lain dari penggabungan. Proses merger memiliki banyak tantangan pada tahap integrasi pascamerger (Trautwein, 1990). Proses integrasi dapat memicu berbagai masalah dan perubahan. Integrasi yang tidak baik dapat menyebabkan kegagalan pada proses merger secara keseluruhan (Shrivastava, 1986). Penelitian ini mencoba melakukan analisis dan merumuskan rekomendasi perancangan Arsitektur enterprise, yang dapat menanggulangi 
masalah-masalah yang akan muncul pada tahap integrasi pascaproses merger. Dengan adanya perancangan arsitektur enterprise yang baik, diharapkan terwujudnya keselarasan antara teknologi informasi dan kebutuhan bisnis. Dengan menggunakan pendekatan tata kelola TI dan TOGAF ADM, maka dirancang tahapan-tahapan Arsiterktur enterprise yang terdiri dari Fase A Arsitektur Visi, Fase B Arsitektur Bisnis, Fase C Arsitektur Sistem Informasi, Fase D Arsitektur Teknologi, dan Fase E Peluang dan solusi. Akhirnya, penelitian ini dapat menghasilkan langkah dan hal penting yang perlu diperhatikan pascaproses merger pada sebuah perguruan tinggi. Langkah tersebut diukur dan dibandingkan terhadap Universitas Telkom yang mengalami proses merger, sehingga diperoleh kesimpulan bahwa rekomendasi perancangan arsitektur enterprise pascamerger sudah sesuai dengan kondisi perguruan tinggi.

Keyword: Merger, Perguruan Tinggi, Arsitektur Enterprise, Togaf ADM, ASW Multicriteria Decission Making

\section{PENDAhuluan}

$\mathrm{B}$ erdasarkan data Dirjen Dikti[3] terdapat 4.217 perguruan tinggi di seluruh Indonesia. Perguruan tinggi tersebut terdiri atas 314 perguruan tinggi negeri (PTN) dan 3.903 perguruan tinggi swasta (PTS). Kondisi ini memicu persaingan dan peningkatan kualitas antarpenyelenggara pendidikan tinggi, terutama perguruan tinggi swasta yang mendominasi pendidikan tinggi di Indonesia. Pada sebuah berita harian Dirjen Pendidikan Tinggi mengatakan bahwa "Jumlah PTS yang ada di Indonesia sangat berlebihan, sehingga untuk mengatasi kelebihan jumlah PTS, pemerintah menunggu proses seleksi alamiah dari PTS yang ada. Pemerintah juga mengarahkan pada merger sejumlah PTS menjadi satu perguruan tinggi, untuk memperkuat operasional mereka." [14].

Merger merupakan kombinasi dari dua atau lebih perusahaan menjadi sebuah perusahaan tunggal yang mencakup akuisi serta bentuk lain dari penggabungan. Merger juga merupakan salah satu langkah yang dapat menjadi solusi bagi enterprise dalam meningkatkan produktivitas, mengurangi biaya, merampingkan proses bisnis dan operasional serta manajerial (Shrivastava, 1986) (Kloosterman, 2005). Oleh karena itu, persaingan yang tinggi dalam dunia bisnis mendorong perusahaan untuk melakukan berbagai macam merger, baik secara horizontal, vertikal, maupun kombinasinya.

Dalam pelaksanaannya, proses merger memiliki banyak tantangan pada tahap integrasi pascamerger (Trautwein, 1990). Integrasi yang tidak baik dapat menyebabkan kegagalan pada proses merger secara keseluruhan (Shrivastava, 1986). Proses integrasi dapat memicu berbagai masalah dan perubahan, seperti keputusan tentang cara penggabungan komponen, termasuk insfrastruktur, proses, aplikasi, SDM, dan budaya. Oleh karena itu, untuk menangani masalah yang akan terjadi pada kasus perguruan tinggi, integrasi pascaproses merger perlu mempertimbangkan beberapa hal penting terkait perancangan arsitektur enterprise diantaranya visi bersama, arahan bisnis, penggunaan sistem informasi, teknologi yang digunakan, budaya organisasi, dan lain sebagainya.

Arsitektur enterprise merupakan cara dalam menggambarkan model enterprise yang mencakup visi arsitektur, perancangan bisnis, operasional bisnis, otomatisasi hingga infrastruktur teknologi informasi pendukungnya. Dengan adanya perancangan arsitektur enterprise yang baik diharapkan terwujudnya keselarasan antara teknologi informasi dan kebutuhan bisnis. Hal tersebut dilakukan agar mengurangi kegagalan dalam implementasi teknologi informasi, khususnya pascaproses merger.

Penelitian ini mencoba membuat rekomendasi atau usulan dalam merancang sebuah arsitektur enterprise pascamerger pada perguruan tinggi, yang akhirnya dapat dimanfaatkan dalam membantu pembuatan arsitektur enterprise, pengambilan suatu keputusan dan tindakan yang bermanfaat pascaproses merger. Penelitian ini akan menggunakan Universitas Telkom sebagai studi kasus penelitian. Universitas Telkom 
merupakan salah satu perguruan tinggi swasta yang mengalami proses merger dari empat perguruan tinggi berbeda sebelumnya, yaitu Institut Teknologi Telkom, STISI Telkom, Institut Manajemen Telkom dan Politeknik Telkom. Sehingga dengan adanya penelitian ini diharapkan proses merger dapat berjalan sesuai dengan tujuan bersama yang diinginkan.

\section{A. Enterprise}

\section{KAJIAN PUSTAKA}

Enterprise merupakan sebuah organisasi atau perusahaan, baik yang memiliki profit maupun tidak. Selain itu enterprise juga didefinisikan sebagai sekumpulan aktifitas yang dilakukan untuk tujuan tertentu. Sehingga, menurut [16] organisasi enterprise dapat dikelompokkan menjadi beberapa kriteria berdasarkan geografis dan kriteria TI. Pengelompokan enterprise secara geografis terdiri dari perusahaan lokal yang bidang penjualannya terbatas pada sebuah kota atau wilayah tertentu, perusahaan nasional, yang penjualannya dalam batas-batas negara, perusahaan internasional yang memiliki divisi internasional, yang beroperasidi negara-negara terpilih, perusahaan multidomestik, yang memungkinkan operasi di negara-negara asing, dan perusahaan global (perusahaan multinasional), yang memungkinkan integrasi operasi yang berlokasi di berbagai Negara.

Sedangkan berdasarkan kriteria TI, organisasi enterprise dapat dikelompokkan menjadi perusahaan offline, dimana pengolahan data beroperasi dalam tumpukan, tidak online dan tidak secara realtime, perusahaan online, yang memproses informasi secara online melalui jaringan komputer, LAN, MAN, WAN, VAN, GAN, dan internet, perusahaan terintegrasi, yang berlaku umum dimana menggunakan database perusahaan untuk sebagian besar aplikasi. Agile enterprise, merupakan enterprise yang bersifat fleksible dan mudah dalam melakukan penyesuaian. perusahaan yang menghasilkan informasi, perusahaan Komunikasi dan perusahaan bergerak.

\section{B. Arsitektur Enterprise}

Menurut [12], enterprise merupakan sekumpulan organisasi yang memiliki seperangkat tujuan. Enterprise dapat diartikan sebuah lembaga pemerintahan, perusahaan keseluruhan, divisi, departemen atau rantai organisasi yang dihubungkan bersama dengan kepemilikan bersama. Enterprise dalam arsitektur enterprise dapat digunakan untuk menunjukkan keseluruhan dari perusahaan, yang mencakup semua informasi dan teknologi layanan, proses dan infrastruktur serta domain tertentu dalam sebuah perusahaan. Dalam kasus yang terjadi, arsitektur melintasi beberapa sistem, dan beberapa kelompok fungsional dalam perusahaan.

Model operasi bisnis ini berguna untuk menentukan sifat dan ruang lingkup arsitektur perusahaan dalam sebuah organisasi. Perusahaan besar atau pemerintahan terkadang memiliki banyak perusahaan (enterprise) di dalamnya. Masing masing perusahaan akan memiliki arsitektur sendiri didalamnya. Untuk itu terkadang banyak kesamaan tentang sistem informasi di masing-masing perusahaan. Sehingga dengan menggunakan kerangka arsitektur berpotensi memperoleh keuntungan yang besar.

\section{Merger dan Acquisition}

Merger merupakan proses kombinasi dari dua perusahaan atau lebih dimana hanya satu perusahaan yang bertahan dan perusahaan yang di merger dan perusahaan merger keluar dari eksistensinya selama ini. Selain itu, merger juga didefinisikan sebagai penggabungan usaha dimana dua atau lebih perusahaan membentuk sebuah perusahaan yang benar-benar baru. Proses merger dapat disesuaikan dengan tujuan dan visi yang telah ditetapkan oleh masing-masing enterprise yang menjalankan.

Disamping itu, pada proses merger juga dikenal istilah akuisisi. Akuisisi merupakan proses pengambilalihan, dimana biasanya akuisisi mengacu pada satu perusahaan pembeli, yang melakukan pembelian aset dengan pembayaran tunai atau pembelian surat berharga kepada perusahaan penjual. Dengan asumsi aset yang dibeli akan menghasilkan keuntungan dan nilainya akan bertambah. Pengimplementasian proses akuisisi juga disesuaikan dengan visi dan target yang ditentukan oleh masing-masing enterprise. 
Menurut [2] merger dan acquisition dilakukan karena beberapa hal yaitu untuk menciptakan dan memanfaatkan sinergitas perusahaan, meningkatkan pangsa pasar, melindungi pasar dengan melemahkan atau menghilangkan saingan, untuk mendapatkan produk ataupun teknologi, untuk memperkuat bisnis dengan memperluas area kompetensi, untuk mendapatkan pijakan di negara lain, dan untuk meningkatkan daya saing (kompetitif).

Ada tiga tahapan menurut [2] yang terjadi dalam proses merger,yaitu tahap perencanaan sebelum merger (pre-merger Planning), proses inti merger, dan integrasi pascaproses merger (post-Merger integration) sebagaimana terlihat pada gambar 1 berikut.

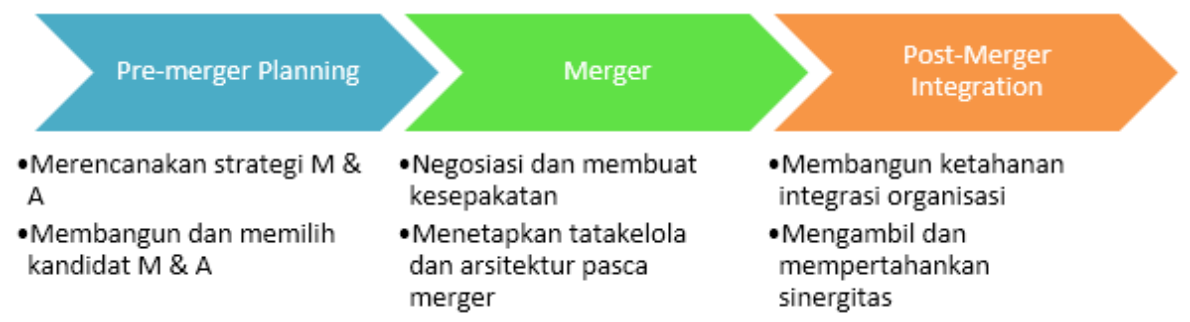

Gambar 1. Tahapan merger[2]

Perencanaan pasca merger memiliki berbagai metode diantaranya berdasarkan (Mehta dan Hirschheim 2007) dapat menggunakan framework pengambil keputusan integrasi sistem informasi (IS Integration Decision Making Framework) yang mengacu pada komponen peyelarasan strategi Hirschheim and Sabherwal sehingga dapat menjadi panduan dalam integrasi pasca merger. Selain itu, menurut (Wijnhoven, Spil, Stegwee and Fa (2006) mengusulkan sebuah model yang dapat memilih dari daftar yang tersedia berdasarkan tujuan merger dan tujuan integrasi IT. Model strategi penyelarasan tersebut mengacu pada Henderson dan Venkataraman's (1993) yang memberikan seperangkat pilihan metode Integrasi sistem informasi untuk berbagai tujuan integrasi maupun merger. Model ini dapat membantu memilih metode integrasi dalam menjaga keselarasan strategi selama proses $M$ \& A. [21]

Dalam mengelola level integrasi, (Vernadat (2007)) mengusulkan sebuah framework kategori interoperabilitas berdasarkan konsep inter-operability. Tahap pertama , jika salah satu perusahaan bertujuan untuk mencapai koordinasi dengan perusahaan lain, maka diperlukan integrasi pada tingkat bisnis. Kedua, jika salah satu perusahaan ingin memiliki kerjasama dengan perusahaan lain, maka diperlukan integrasi pada level aplikasi dan terakhir, jika salah satu perusahaan bertujuan membangun interoperobilitas komunikasi, maka diperlukannya integrasi pada level fisik. Model ini dapat membantu memberikan kombinasi integrasi sesuai dengan tujuan yang diinginkan.

Berdasarkan framework diatas selama transformasi proses M \& A, [20] mengusulkan adanya level integrasi data dan level dari standardisasi proses bisnis dalam menjalankan model operasi sebuah organisasi. Selain itu, jika proses bisnis integrasinya tinggi, maka datapun harus terintegrasi untuk meningkatkan proses integrasi yang ada.

Menurut Mo and Nemes (2009) dalam [21] menyebutkan bahwa proses M \& A dapat menggunakan pendekatan metodologi teknik yang kuat sehingga dibutuhkan perencanaan aktivitas sistematis agar menghasilkan transisi yang rapi selama prosesnya. Salah satu kerangka sistematis menurut Bernus and Nemes (2003) pada [21] dalam segala aspek perubahan pada sebuah enterprise disebut kerangka arsitektur enterprise. Arsitektur enterprise memiliki kemampuan dalam mendukung pengambilan keputusan pada perubahan bisnis, karena memiliki model bisnis dan model teknis.

Beberapa metode yang digunakan dalam arsitektur enterprise sebagaimana terdapat pada Tabel I berikut:[21]

TABEL I 


\begin{tabular}{|l|l|}
\hline No & \multicolumn{1}{|c|}{ Kerangka(Framework) } \\
\hline 1 & $\begin{array}{l}\text { PERA (Purdue Enterprise Reference Architecture) - (Williams, 1994). Metode ini menunjukkan } \\
\text { perancangan suatu perusahaan melalui siklus hidupnya. }\end{array}$ \\
\hline 2 & $\begin{array}{l}\text { CIMOSA (Computer Integrated Manufacturing Open Systems Architecture) - (AMICE 1993). } \\
\text { Metode ini membantu mengidentifikasi spesifikasi, desain dan implementasi suatu kegiatan } \\
\text { perusahaan serta mendefinisikan makna dari model yang dirujuk. }\end{array}$ \\
\hline 3 & $\begin{array}{l}\text { GRAI GIM (Chen, Vallespir \& Doumeingts, 1997). Menjelaskan metodologi dan mereferensikan } \\
\text { tingkat perbedaan masing-masing komponen enterprise yang saling terhubung datu dan lainnya } \\
\text { dalam siklus hidup sebuah perusahaan. }\end{array}$ \\
\hline 4 & $\begin{array}{l}\text { GERAM (Generalised Enterprise Reference Architecture and Methodology). Merupakan dasar dari } \\
\text { Standar Internasional EA frameworks (ISO 15704:2000, 2005) }\end{array}$ \\
\hline 5 & $\begin{array}{l}\text { The Open Group Architecture Framework (TOGAF) - (2009). Metode ini berfokus pada bidang } \\
\text { teknologi informasi. }\end{array}$ \\
\hline 6 & Zachman Framework - (Zachman, 1987) \\
\hline
\end{tabular}

\section{TOGAF (The Open Group Architecture Framework)}

Framework arsitektur merupakan sebuah struktur dasar atau sekumpulan struktur yang dapat digunakan untuk mengembangkan berbagai arsitektur yang berbeda. Framework akan menjelaskan metode untuk merancang kondisi yang diharapkan dari sebuah enterprise. Framework juga mencakup daftar standar yang direkomendasikan untuk mengimplementasikan sebuah arsitektur.

Menurut Zachman atau TOGAF, framework merupakan sebuah alat (tool) yang digunakan untuk memikirkan sesuatu dan mengkategorikan informasi yang dibutuhkan untuk merekam(menggambarkan) sebuah organisasi, untuk mengerti bagaiman alur proses bekerja dan menjadikan sekumpulan sistem informasi yang mendukung bisnis secara efisien. [18]

\section{E. TOGAF ADM (The Architecture Development Method)Fdvdf}

TOGAF ADM merupakan hasil kontribusi dari sejumlah besar praktisi arsitektur. Metode ini menjelaskan cara mengembangkan dan mengelola siklus arsitektur enterprise. TOGAF ADM menangani integrasi unsur dalam memenuhi kebutuhan bisnis dan TI organisasi. ADM adalah sebuah penjelasan detail, langkah demi langkah metode dilakukan, bagaimana dibangun, di kelola dan di implementasikannya sebuah arsitektur enterprise.

TOGAF ADM adalah bagian utama dari TOGAF. Hal yang utama dari ADM adalah manajemen kebutuhan. Bisnis, sistem informasi dan arsitektur teknologi akan selalu selaras dengan kebutuhan dan sesuai dengan tujuan bisnis. Pada Gambar 2 merupakan beberapa langkah pembangunan arsitektur enterprise menurut TOGAF ADM [12].

FASE A - Visi arsitektur (Architechture Vision ). Fase ini menggambarkan fase awal dari ADM. Didalamnya terdapat informasi mengenai pendefinisian ruang lingkup, mengidentifikasi stakeholder, menciptakan visi dari arsitektur yang akan dibuat serta mendapatkan persetujuan akan hal itu. FASE B Arsitektur Bisnis (Business Architechture). Fase ini menggambarkan pembangunan arsitektur bisnis untuk mendukung terwujudnya visi arsitektur, FASE C - Arsitektur sistem informasi (Information System Architechture). Fase ini menggambarkan arsitektur sistem informasi pada proyek arsitektur, termasuk didalamnya terdapat pengembangan arsitektur data dan aplikasi, FASE D - Arsitektur Teknologi (Technology Architechture). Fase ini membangun arsitektur teknologi yang dimulai dari penentuan kandidat teknologi yang diperlukan dengan menggunakan teknologi portofolio, FASE E - Peluang dan solusi (Opportunities and solutions), FASE F - Rencana Migrasi (Migration Planning), FASE G - Tata kelola implementasi (Implementation Governance), dan FASE H - Arsitektur manajemen perubahan (Architechture Change Mangement). 
INDRA LUKMANA SARDI et al:

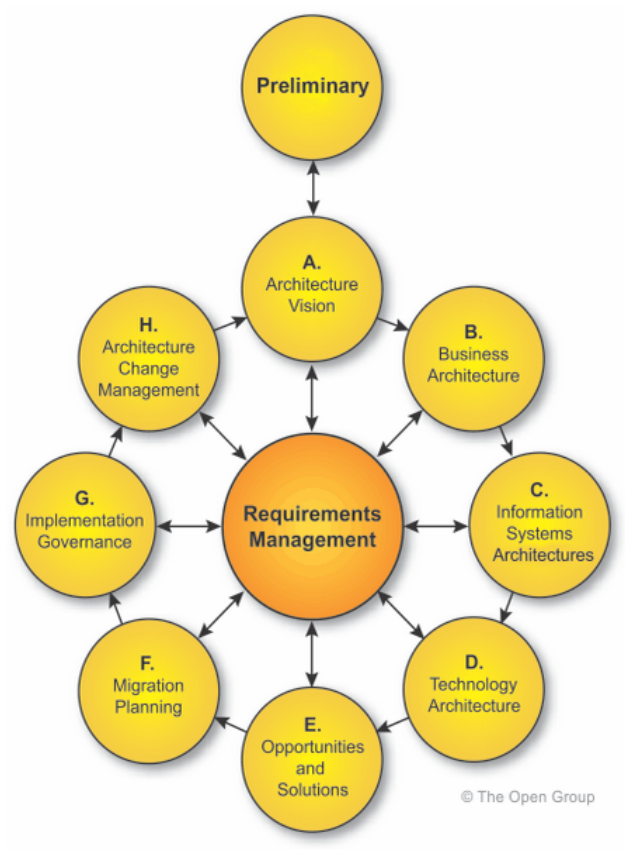

Gambar 2. TOGAF ADM [12]

\section{F. Paradigma Organisasi}

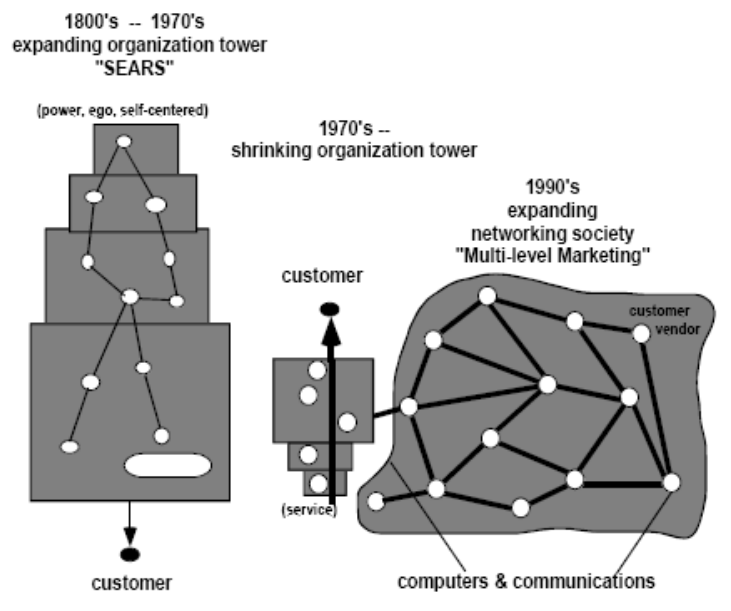

Gambar 3. Pergeseran model hirarki menuju model jaringan [16]

Manajemen perusahaan saat ini mengalami pergeseran paradigma yang disebabkan oleh aplikasi teknologi informasi. Hal ini menyebabkan munculnya pendefinisian aturan bisnis baru. Perubahan yang terjadi pada sebuah orgnisasi akan mempengaruhi organisasi bisnis yang sedang berjalan. Untuk itu perlunya mengetahui sifat perubahan dan bagaimana mengatasinya, sehingga "future shock" dapat dihindari. Berikut beberapa pergeseran paradigma yang terjadi [16] yaitu a. Pergeseran kekuatan. Pergeseran paradigma yang paling mudah dikenali yaitu pada perspektif politik, perspektif ekonomi dan perspektif social, b. Pergeseran pada strategi sumber daya. Pergeseran paradigma dari sumber daya terjadi dari kebutuhan sumber daya yang banyak ke sumber saya yang lebih sedikit, dari kuantitas dan kualitas, ke pengurangan waktu sumber daya. 
Sumber daya manusia yang dibutuhkan juga akan lebih sedikit, c. Pergeseran pada struktur enterprise. Pergeseran ini mengakibatkan hal yang kompleks dan meningkatkan ukuran sebuah organisasi bisnis dan d. Pergeseran pada kontrol manajemen. Pergeseran dari model hirarki menuju model jaringan. Pergeseran yang terjadi dari kepemimpinan tunggal dalam sebuah organisasi menjadi organisasi asosiasi, fleksibel yang disatukan oleh visi bersama yang telihat pada gambar 3 .

\section{G. Sentralisasi dan desentralisasi}

Terdapat dua pendekatan dalam management organisasi yang akan terjadi pada proses merger, yaitu pendekatan terpusat (Sentralisasi) dan pendekatan tersebar (Desentralisasi) yang terlihat pada gambar 4 berikut.

\begin{tabular}{|c|c|}
\hline SENTRALISASI & DESENTRALISASI \\
\hline $\begin{array}{l}\text { - KEUNTUNGAN } \\
\text { - Berbagi sumber daya } \\
\text { - Menghindari duplikasi } \\
\text { - Mempermudah dalam memahami dan } \\
\text { melakukan kontrol (keamanan) } \\
\text { - Pencapaian skala Ekonomi } \\
\text { - KENDALA dan KERUGIAN } \\
\text { - Teknis (perbedaan data, aplikasi dan jaringan } \\
\text { ketika kondisi tersebar) } \\
\text { - Keterbatasan Sumber daya (uang, waktu SDM, } \\
\text { Keterampilan) } \\
\text { - Politik, budaya, struktural } \\
\text { - Membutuhkan waktu } \\
\text { - Banyak penundaan } \\
\text { - Kemampuan terbatas dalam memenuhi } \\
\text { kebutuhan } \\
\text { - Kekakuan dalam mengatasi perubahan } \\
\text { - Peningkatan ketergantunganakibat banyaknya } \\
\text { staf, keterhgantungan dengan staf kunci, } \\
\text { kompleksitas yang besar, Keamanan }\end{array}$ & $\begin{array}{l}\text { - KEUNTUNGAN } \\
\text { - Kecocokan sistem dan kebutuhan lokal } \\
\text { - Pembangunan sistem yang lebih cepat } \\
\text { - Biaya rendah } \\
\text { - KENDALA } \\
\text { - Hambatan dalam berbagi data dan sumber } \\
\text { daya } \\
\text { - Duplikasi usaha } \\
\text { - Hambatan dalam melakukan kontrol } \\
\text { - Galal dalam pencapaain skala ekonomi }\end{array}$ \\
\hline
\end{tabular}

Gambar 4. Sentralisasi dan Desentralisasi

\section{H. Tata kelola TI}

Untuk menghasilkan keputusan yang efektif, perlu adanya perhatian dan tatakelola pada lima kunci utama yang saling berhubungan dalam sebuah keputusan, sehingga hasil keputusan akan berjalan dengan baik. Lima kunci utama[20] tersebut yaitu keputusan mengenai Prinsip TI. Pernyataan tingkat tinggi mengenai bagaimana TI secara umum akan digunakan dalam sebuah bisnis, keputusan mengenai Arsitektur TI, pengaturan secara logic terhadap data, aplikasi dan infrastruktur yang dilihat dalam sekelompok kebijakan, keterhubungan dan pilihan secara teknis untuk memenuhi keinginan bisnis dan standardisasiteknis serta integrasi, keputusan Mengenai Infrastruktur TI, koordinasi terpusat, Layanan bersama yang menyediakan dasar bagi suatu kemampuan TI sebuah enterprise, keputusan mengenai kebutuhan aplikasi bisnis, menentukan kebutuhan bisnis dalam pengadaan/pembelian aplikasi TI atau pembangunan TI secara interna,1 dan keputusan mengenai investasi dan prioritas TI, keputusan mengenai bagaimana dan dimana akan dilakukan investasi TI, termasuk persetujuan proyek TI dan keputusan teknis.

\section{Gartner Magic Quadrant}

Gartner Magic Quadrant [6] merupakan sebuah metodologi untuk memberikan pandangan mengenai posisi relatif dari persaingan pasar. Dengan menggunakan grafik serta satu set kriteria evaluasi seragam, metode ini 
dapatdengan cepat membantu pengguna dalam memahami bagaimana penyedia teknologi menjalankan visi yang telah mereka jabarkan. Gartner Magic Quadrant digunakan untuk memahami penyedia teknologi yang ada, sehingga dapat memudahkan dalam mempertimbangkan dalam peluang investasi tertentu.

Metodologi penelitian Gartner Magic Quadrant yang terlihat pada Gambar 5 memberikan posisi kompetitif secara grafis dari empat jenis penyedia teknologi di pasar yang tumbuh dengan cepat, yaitu:

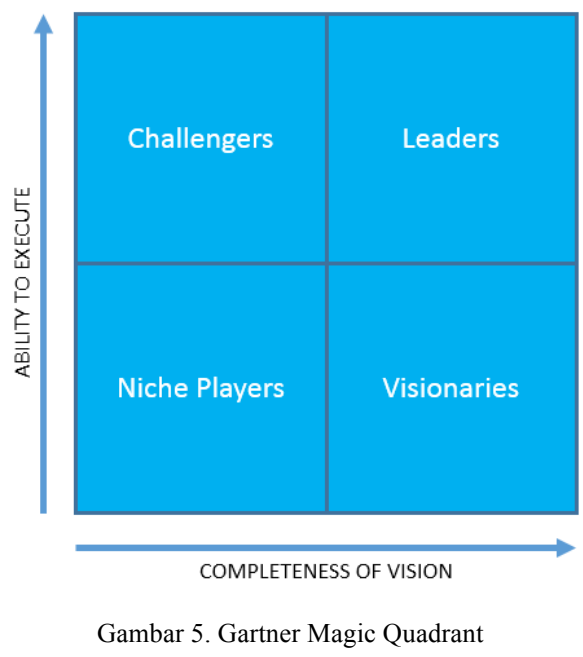

Leader: Tipe ini mengeksekusi dengan baik terhadap visi saat ini dan memiliki posisi yang baik untuk masa depan. Visioner: Tipe ini memahami kondisi pasar atau memiliki visi untuk mengubah aturan pasar, akan tetapi belum dieksekusi dengan baik. Niche Players: Tipe ini fokus pada kesuksesan di segmen kecil, atau tidak fokus dalam inovasi dan tidak mengungguli yang lain dan Challengers: Tipe ini mengeksekusi dengan baik hari ini atau mungkin mendominasi segmen besar, tetapi tidak menunjukkan pemahaman mengenai arah pasar.

\section{J. Simple Additive Weighting Method (SAW)}

Metode Simple Additive Weighting Method (SAW) sering juga dikenal istilah metode penjumlahan terbobot. Konsep dasar metode SAW adalah mencari penjumlahan terbobot dari rating kinerja pada setiap alternatif pada semua atribut. Metode SAW membutuhkan proses normalisasi matriks keputusan (X) ke suatu skala yang dapat diperbandingkan dengan semua rating alternatif yang ada.

Berikut adalah Algoritma FMADM-SAW menurut [11]:

a) Memberikan nilai setiap alternatif (Ai) pada setiap kriteria $(\mathrm{Cj})$ yang sudah ditentukan, dimana nilai tersebut di peroleh berdasarkan rating kecocokan setiap alternatif. Ai (alternatif ke i) $=1,2, \ldots \mathrm{m}$. Aj (Alterntif ke-j)=1,2,...n.. Rating kecocokan setiap alternatif: 1=Sangat Buruk, 2=Buruk, 3=Cukup, 4=Baik, 5=Sangat Baik

b) Memberikan nilai bobot (W) yaitu kecocokan dari setiap alternatif yang juga didapatkan berdasarkan nilai pembobotan kepentingan kriteria ( $1=$ Sangat Rendah, 2=Rendah, 3=Cukup, 4=Tinggi, 5=Sangat Tinggi).

c) Melakukan normalisasi matriks dengan cara menghitung nilai rating kinerja ternormalisasi (rij) dari alternatif $\mathrm{Ai}$ pada atribut $\mathrm{Cj}$ berdasarkan persamaan yang disesuaikan dengan jenis atribut (atribut keuntungan $/$ benefit $=$ MAKSIMUM atau atribut biaya/cost $=$ MINIMUM). Apabila berupa artibut keuntungan maka nilai crisp (Xij) dari setiap kolom atribut dibagi dengan nilai crisp MAX (MAX Xij) dari tiap kolom, sedangkan untuk atribut biaya, nilai crisp MIN (MIN Xij) dari tiap kolom atribut 
dibagi dengan nilai crisp (Xij) setiap kolom.Melakukan proses perankingan dengan cara mengalikan matriks ternormalisasi (R) dengan nilai bobot (W).Adapun rumus untuk menentukan matriks ternormalisasi $\mathrm{R}$ adalah sebagai berikut:

$$
r_{i j}=\left\{\begin{array}{l}
\frac{x_{i j}}{\operatorname{Max} x_{i j}} \text { jika j adalah atribut keuntungan (benefit) } \\
i \text { Min } x_{i j} \\
\frac{i}{x_{i j}} \text { jika j adalah atribut biaya (cost) }
\end{array}\right.
$$

d) Menentukan nilai preferensi untuk setiap alternatif (Vi) dengan cara menjumlahkan hasil kali antara matriks ternormalisasi (R) dengan nilai bobot (W). Nilai Vi yang lebih besar mengindikasikan bahwa alternatif Ai lebih terpilih.

\section{Metode PenELITIAN}

Tahap perancangan dibagi menjadi tiga bagian, yaitu pra pengolahan, perancangan arsitektur enterprise dan hasil rekomendasi Perancangan arsitektur enterprise.

\section{A. Pra Pengolahan}

Bagian pertama pra-pengolahan merupakan bagian mengidentifikasi kondisi awal lingkungan kasus. Mengidentifikasi proses merger yang terjadi di perguruan tinggi baik dari sudut pandang organisasi, infrastruktur, aplikasi yang telah ada berjalan dan kebijakan yang ada. Hasil identifikasi tersebut akan digunakan dalam proses-proses selanjutnya sehingga bagian ini dianggap penting dalam menyelesaikan kasus merger.

Sumber data yang dibutuhkan diperoleh dari berbagai sumber, yang dikelompokkan berdasarkan sumber data sebagai berikut:

\section{1). Data Primer.}

Data primer diperoleh dari sumber aslinya. Data ini didapat melalui wawancara dan diskusi langsung dengan pihak organisasi, maupun pengamatan langsung dilapangan. Data primer yang dibutuhkan mengenai proses merger, kondisi organisasi saat merger, dan harapan yang diharapkan dengan kondisi merger.

\section{2). Data Sekunder.}

Data sekunder merupakan data dalam bentuk dokumen yang diperoleh dari organisasi tempat penelitian dilakukan. Dokumen tersebut dapat diperoleh dari berbagai divisi pada perguruan tinggi kasus, yang terlibat dalam proses merger.

\section{B. Perancangan Arsitektur Enterprise}

Selanjutnya pada bagian kedua, dilakukan perancangan arsitektur enterprise. Perancangan arsitektur enterprise pada tahap ini menggunakan framework TOGAF ADM, karena framework ini memberikan langkah detail dan generik dalam membangun, mengelola serta mengimplementasikan arsitektur enterprise. Menurut [20] dalam sebuah keputusan TI, terdapat 5 kunci utama yang perlu diperhatikan yaitu prinsip TI, arsitektur TI, infrastruktur TI, Kebutuhan aplikasi bisnis dan investasi dan prioritas TI. Kemudian, berdasarkan pemetaan 5 kunci utama yang perlu diperhatikan pada keputusan TI dengan langkah langkah 
pada Togaf ADM, maka diperoleh 5 faktor utama dalam perancangan arsitektur enterprise yang terlihat pada gambar 6 berikut.

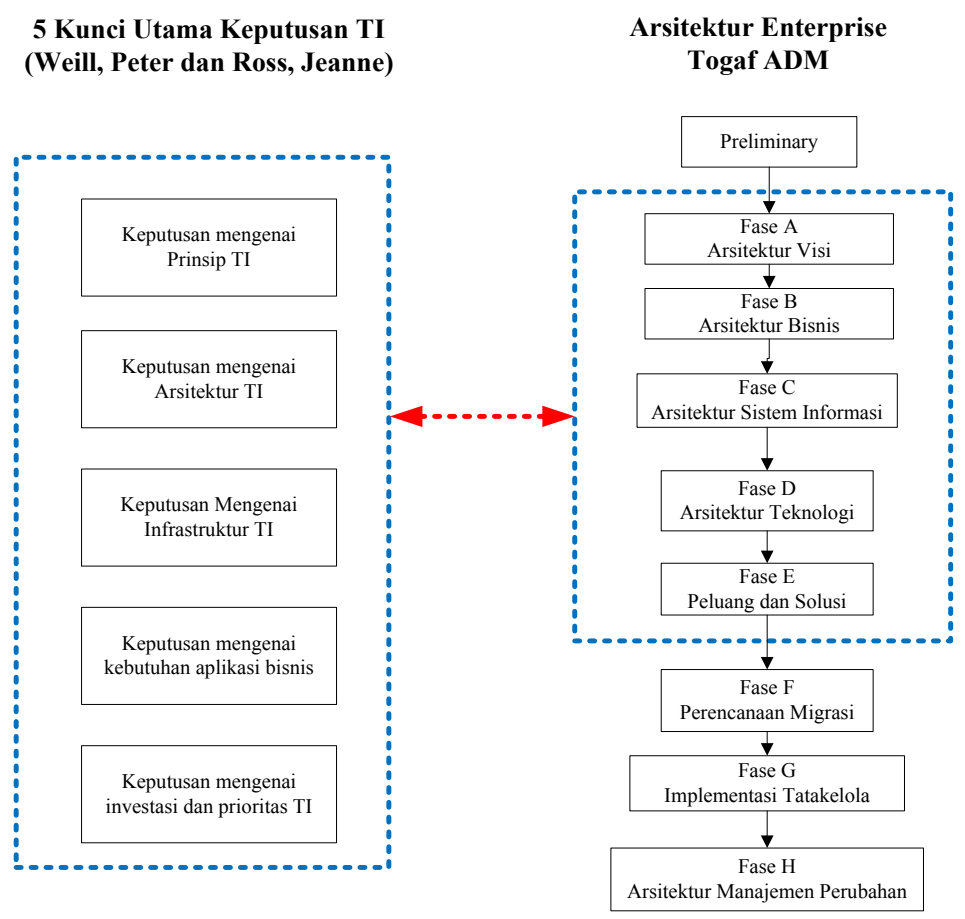

Gambar 6. Pemetaan lima Kunci utama TI dan Togaf ADM

Pada fase A ditentukan visi dalam perencanaan EA, Menyusun visi bersama pada perguruan tinggi hasil merger yang ditetapkan dari hasil perencanaan bersama antara perguruan tinggi yang melakukan merger. Tahap ini bertujuan untuk menyamakan pandangan mengenai pentingnya arsitektur dalam mencapai tujuan organisasi. Dalam pembentukannya, dapat melibatkan masing-masing pimpinan perguruan tinggi, sehingga diperoleh visi bersama yang mengakomodasi masing-masing perguruan tinggi.

Pada Fase B ditentukan arah, model dan aktivitas bisnis yang akan dijalankan perguruan tinggi, dimana berfokus pada Tridharma Perguruan Tinggi berdasarkan UU No. 12 Tahun 2012, Pasal 1 Ayat 9 yang berbunyi, "Tridharma Perguruan Tinggi yang selanjutnya disebut Tridharma adalah kewajiban Perguruan Tinggi untuk menyelenggarakan Pendidikan, penelitian, dan pengabdian kepada masyarakat". Pada tahap ini akan dijelaskan aktifitas utama serta aktivitas pendukung, yang mana mendukung visi yang telah ditentukan sebelumnya.

Secara umum, perguruan tinggi memiliki tiga aktifitas bisnis utama yaitu pendidikan, penelitian dan pengabdian masyarakat yang biasa disebut dengan tridharma perguruan tinggi. Aktifitas tersebut merupakan ciri khas dari perguruan tinggi sebagai sebuah lembaga pendidikan. Aktifitas-aktifitas pendukung, dilaksanakan dalam tujuan mendukung aktifitas utama tersebut. Sehingga tiga aktifitas utama tersebut dapat berjalan sebagai mana mestinya dalam mencapai kesuksesan.

Pada fase $\mathrm{C}$ ditekankan pada pengembangan sistem informasi yang meliputi arsitektur data dan arsitektur aplikasi yang digunakan perguruan tinggi. Dalam pengimplementasiannya arsitektur data diarahkan untuk menggunakan pendekatan terpusat mengingat pemanfaatan, pemeliharaan dan kerahasiaan dari data perguruan tinggi. Untuk data-data yang umum dan penting diletakkan terpusat, sedangkan untuk data yang 
bersifat pribadi diletakkan secara desentralisasi. Hal ini akan mempermudah manajemen dalam pemanfaatan, penjagaan serta perbaikan yang ada.

Pada fase ini dari perancangan arsitektur enterprise juga dihasilkan sebuah portofolio aplikasi. Portofolio aplikasi merupakan gambaran dari aplikasi yang dibutuhkan dan akan digunakan di masa mendatang. Sehingga dapat dipetakan mana aplikasi yang masuk ke dalam kelompok strategis (strategic), potensial tinggi (high potential), operasional (key operational), dan pendukung (support) sebagaimana terlihat pada gambar 7. Dengan demikian dapat diurutkan prioritas pengembangan aplikasi yang akan dilakukan sebuah organisasi.

\begin{tabular}{|l|l|}
\hline \multicolumn{1}{|c|}{ STRATEGIC } & \multicolumn{1}{c|}{ HIGH POTENTIAL } \\
\hline $\begin{array}{l}\text { Aplikasi yang kritis untuk } \\
\text { mempertahankan strategi bisnis } \\
\text { kedepan }\end{array}$ & $\begin{array}{l}\text { Aplikasi yang cukup penting dalam } \\
\text { mencapai keberhasilan dimasa depan }\end{array}$ \\
\hline $\begin{array}{l}\text { Aplikasi dimana organisasi saat ini } \\
\text { bergantung agar mencapai } \\
\text { keberhasilan }\end{array}$ & $\begin{array}{l}\text { Aplikasi yang berharga tetapi tidak } \\
\text { penting dalam mencapai keberhasilan }\end{array}$ \\
\hline \multicolumn{1}{|c|}{ KEY OPERATIONAL } & SUPPORT \\
\hline
\end{tabular}

Gambar 7. Portofolio Aplikasi

Pada fase D arsitektur teknologi, dilakukan penyesuaikan terkait data yang dilakukan terpusat, sehingga jaringan yang dibentuk akan melakukan pendekatan terpusat. Pendekatan terpusat ini juga sejalan dengan adanya pemanfaatan teknologi perangkat yang pada kasus perguruan tinggi digunakan dalam proses bisnis utama. Sehingga kesemua perangkat dapat terhubung kejaringan dan memanfaatkan data yang ada. Beberapa hal yang perlu diperhatikan pada arsitektur teknologi yaitu perangkat yang digunakan dalam aktivitas, media penyimpanan data dan jaringan sebagai sarana penghubung.

Selanjutnya, pada Fase E peluang dan solusi, dilakukannya analisis GAP antara kondisi saat ini dan kondisi masa depan. Pada kasus merger masing-masing organisasi telah memiliki bisnis, infrastruktur, serta data dan aplikasi, sehingga pasca merger akan ditemui beberapa hal yang redundan sebagaimana terlihat pada gambar Gambar 8 sebagai berikut.

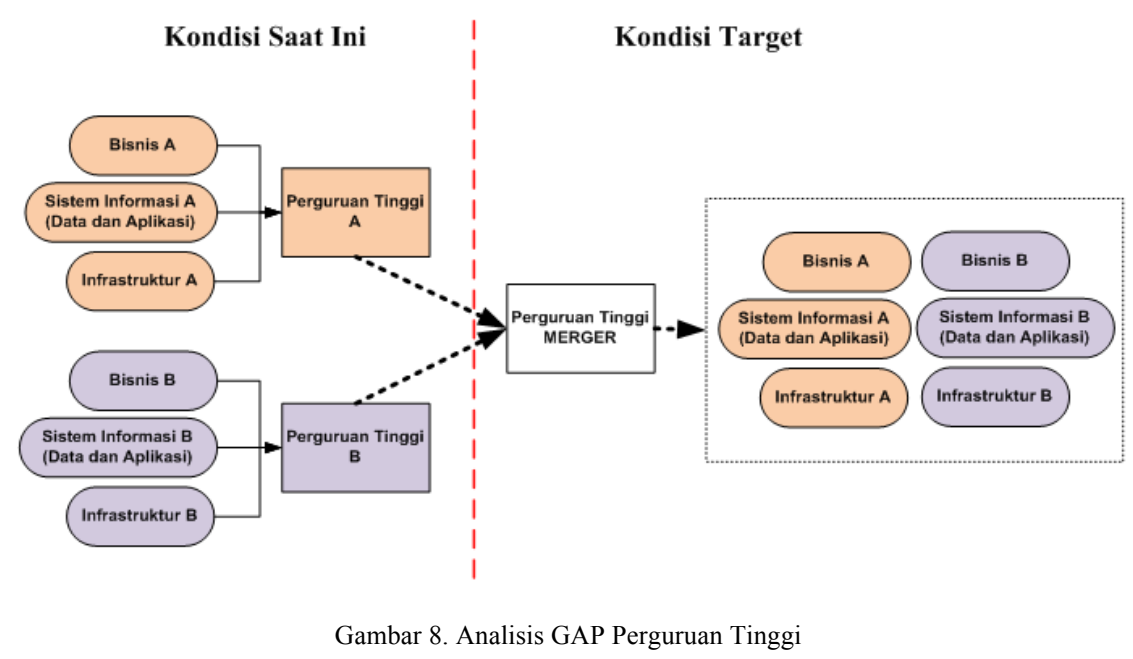

Dengan demikian, setelah melakukan proses merger organisasi harus memutuskan langkah apa yang perlu diambil pada sektor bisnis, sistem informasi dan infrastruktur. Pada bagian perancangan bisnis telah 
ditentukan bisnis utama perguruan tinggi akan mengacu pada tridharma perguruan tinggi, sehingga pada sektor bisnis dapat dilakukan standardisasi. Selanjutnya pada bagian data dan aplikasi, memiliki beberapa pilihan yaitu membuat aplikasi baru, membangun middleware, atau memilih satu dari aplikasi yang ada dari salah satu organisasi yang dianggap baik. Sedangkan untuk infrastruktur mengikuti kondisi sistem informasi yang ada, sehingga perlu dilakukannya integrasi.

Oleh karena itu, dalam penelitian ini diteliti opsi memilih aplikasi dari beberapa aplikasi yang telah ada pascamerger, sehingga dapat membantu organisasi dalam mengambil keputusan memilih aplikasi mana yang baik dan sesuai dengan yang mereka butuhkan kedepannya. Dalam implementasinya, pemilihan aplikasi membutuhkan kriteria dalam memutuskan aplikasi mana yang akan digunakan, sehingga kriteria-kriteria yang ada dapat membantu dalam proses seleksi.

\section{Kriteria pemilihan aplikasi}

Kriteria yang digunakan dalam penelitian ini merujuk pada kriteria penentuan kualitas sistem yang disusun dalam Kriteria Kualitas Perangkat Lunak ISO 25010, Kriteria Informasi Cobit 4.1, Dimensi Kualitas Informasi [1], Kriteria Kualitas Informasi[10] yang terdiri dari berbagai kriteria umum informasi. Berdasarkan perbandingan kriteria yang ada, maka diperoleh sebagaimana pada Tabel II berikut:

TABEL II

KRITERIA INFORMASI

\begin{tabular}{|l|l|}
\hline \multicolumn{1}{|c|}{ Kriteria } & \multicolumn{1}{c|}{ Keterangan } \\
\hline Kesesuaian Fungsionalitas & Kelayakan, Ketepatan, Kesesuaian dalam pemenuhan kebutuhan bisnis \\
\hline Keandalan & $\begin{array}{l}\text { Ketersediaan, toleransi kesalahan, pemulihan dalam pemenuhan } \\
\text { pemenuhan kebutuhan }\end{array}$ \\
\hline Efisiensi & Waktu perilaku, pemanfaatan sumber daya \\
\hline Operabilitas & $\begin{array}{l}\text { Kelayakan, Dapat dikenali, Dapat dipelajari, Kemudahan penggunaan, } \\
\text { Berdaya Bantu, Atraktif, Teknis,Dapat diakses, Pemenuhan kebutuhan }\end{array}$ \\
\hline Keamanan & $\begin{array}{l}\text { Kerahasiaan, Integritas, Tidak adanya penyangkalan, Akuntabilitas, } \\
\text { Keaslian, Pemenuhan kebutuhan }\end{array}$ \\
\hline Portabilitas & Dapat melakukan penyesuaian, Dapat di install dan memenuhi kebutuhan \\
\hline
\end{tabular}

$$
\text { IV. HASIL DAN DISKUSI }
$$

Berdasarkan penelitian yang dilakukan, maka dapat dirumuskan perancangan Arsitektur enterprise untuk sebuah kasus merger sebagaimana terlihat pada Gambar 9, yaitu dengan melakukan adopsi pemanfaatan arsitektur enterprise. Tahap awal menganalisis arsitektur visi, arsitektur bisnis, arsitektur sistem informasi, arsitektur teknologi dan melihat peluang dan solusi. Keseluruhan tahap tersebut di perbandingkan dengan kondisi merger pada Universitas Telkom sebagai studi kasus yang digunakan. 


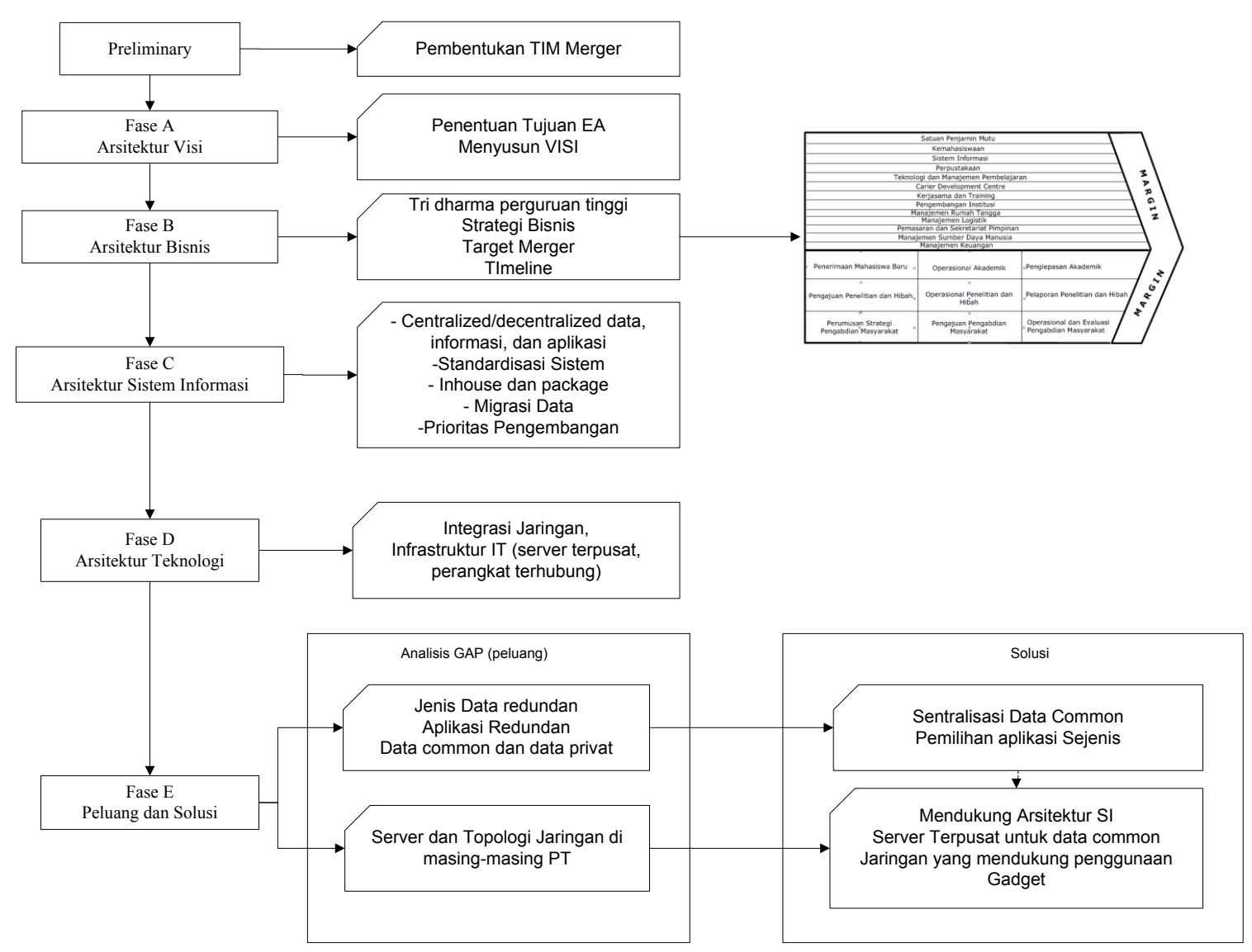

Gambar 9. Rekomendasi perancangan Arsitektur Enterprise

Perancangan EA menggunakan TOGAF ADM merupakan salah satu metode yang telah teruji dan dapat digunakan dalam merancang EA perguruan tinggi, sehingga langkah per langkah tidak perlu divalidasi. Dalam rekomendasi perancangan ini, yang diperlukan adalah evaluasi kesesuaian antara rekomendasi perancangan dengan studi kasus yang ada, yakni perguruan tinggi kasus (Universitas Telkom).

Sehingga, pada tahap evaluasi dilakukan pengecekan terhadap rekomendasi perancangan berdasarkan studi literatur yang telah dilaksanakan. Lingkungan studi kasus di-capture dan dipetakan terhadap rekomendasi yang telah dirancang agar dapat diketahui apa yang belum dilakukan dan patut menjadi bahan pertimbangan dalam perbaikan perancangan, sehingga diperoleh sebuah rekomendasi yang baik secara keilmuan dan sesuai dengan kondisi studi kasus.

Berdasarkan rekomendasi perancangan arsitektur enterprise yang ada, maka dilakukan wawancara terhadap 6 orang pihak terkait yang masing-masing merepresentasikan bagian yang terlibat dalam proses merger pada studi kasus yaitu Direktur Aliansi Strategis Yayasan Pendidikan Telkom, Ketua Tim Implementasi dan Transformasi Universitas Telkom, Rektor Universitas Telkom, Ketua tim pembentukan struktur organisasi, Ketua Tim Transformasi sistem informasi, dan Anggota Tim Transformasi Sistem informasi., sehingga diperiksa apa saja yang yang telah dilakukan dalam proses merger pada Universitas Telkom yang ditunjukkan pada Tabel III. 


\begin{tabular}{|c|c|c|c|}
\hline \multirow{2}{*}{$\begin{array}{c}\text { Tahapan Arsitektur } \\
\text { Enterprise }\end{array}$} & \multirow{2}{*}{ Kriteria } & \multicolumn{2}{|c|}{ Kondisi Lapangan } \\
\hline & & Ada & Belum \\
\hline Preliminary & Pembentukan Tim Merger & $\mathrm{V}$ & \\
\hline Arsitektur Visi & $\begin{array}{l}\text { Penentuan visi bersama oleh perwakilan pimpinan } \\
\text { masing-masing perguruan tinggi dan pihak-pihak yang } \\
\text { berkepentingan }\end{array}$ & $\mathrm{V}$ & \\
\hline \multirow{5}{*}{ Arsitektur Bisnis } & Pembuatan struktur organisasi & $\mathrm{V}$ & \\
\hline & Tri dharma perguruan tinggi sebagai bisnis utama & $\mathrm{V}$ & \\
\hline & Strategi Bisnis & $\mathrm{V}$ & \\
\hline & Target Merger & $\mathrm{V}$ & \\
\hline & Timeline Merger & $\mathrm{V}$ & \\
\hline \multirow{4}{*}{$\begin{array}{l}\text { Arsitektur Sistem } \\
\text { Informasi }\end{array}$} & Centralized/Decentralized Data & $\mathrm{V}$ & \\
\hline & Standardisasi Sistem & $\mathrm{V}$ & \\
\hline & Migrasi Data & $\mathrm{V}$ & \\
\hline & Prioritas Pengembangan/Timeline & $\mathrm{V}$ & \\
\hline \multirow[t]{2}{*}{ Arsitektur Teknologi } & Integrasi Jaringan & $\mathrm{V}$ & \\
\hline & Pemusatan Server & $\mathrm{V}$ & \\
\hline
\end{tabular}

Berdasarkan pemetaan antara rekomendasi dan studi kasus, diperoleh kesimpulan bahwa hal-hal penting yang perlu diperhatikan dalam rekomendasi perancangan arsitektur enterprise pascamerger sudah sesuai dengan kondisi perguruan tinggi, yang mana keseluruhan daftar telah dilaksanakan pada studi kasus.

\section{KESIMPULAN}

Kesimpulan yang diperoleh dari penelitian ini adalah sebagai berikut:

1. Dalam pembuatan arsitektur enterprise pada perguruan tinggi berfokus pada proses bisnis aktifitas utama yaitu pendidikan, penelitian dan pengabdian masyarakat, yang kesemua aktifitas dan dukungan di dalamnya dilaksanakan untuk mendukung proses tersebut.

2. Pada fase arsitektur data pascamerger sebaiknya menggunakan pendekatan terpusat dikarenakan keamanan data, maintenance, dan mengurangi keberadaan data yang duplikasi.

3. Pada aplikasi yang redundan, dapat disolusikan dengan melakukan pemilihan aplikasi, dengan melakukan klasifikasi menggunakan portofolio aplikasi serta dipilih mana yang paling sesuai menggunakan multicriteria decission making ataupun Magic Quadrant Gartner.

4. Rekomendasi perancangan arsitektur enterprise pascamerger dapat diterapkan pada kasus merger Universitas Telkom, karena sudah sesuai dengan kondisi di perguruan tinggi.

\section{REFERENSI}

[1] Al-Hakim, L. (2007). Information Quality. Australia: IdeA Group publishing.

[2] Bohlin, N. D. (2014, Mei 14). Successful Post-Merger Integration: Realizing the Synergies. Dipetik Mei 14, 2014, dari http://www.imaa-institute.org/: http://www.imaa-institute.org/

[3] Dirjen Dikti. (2014, Februari). Data Perguruan Tinggi. Diambil kembali dari https://forlap.dikti.go.id/

[4] Donald Dawson, S. W. (2010). The Role of IT in Successful Merger Integration. Booz \& Company.

[5] Engineering, Departement of Software and IT. (2008, Juli 17). ISO 25010.2, Software engineering-Software product Quality.

[6] Gartner, I. (2015, 01 10). Gartner. Diambil kembali dari Gartner Magic Quadrant: http://www.gartner.com/technology/research/methodologies/research_mq.jsp

[7] Heeks, R. (1999). Centralised vs. Decentralised Management of Public Information Systems: A Core-Periphery Solution. Information Systems for Public Sector Management. Institute for Development Policy and Management.

[8] Henningsson, S. (2008). Managing Information Systems Integration in Corporate Mergers and Acquisitions. Lund Institute of Economic Research School of Economics and Management.

[9] IT Governance Institut. (2007). Cobit 4.1 Excerpt. United States of America: IT Governance Institut.

[10] J.Eppler, M. (2006). Managing Information Quality. Heidelberg NewYork: Springer.

[11] Kusumadewi, S., Hartati, S., Harjoko, A., \& Wardoyo, R. (2006). Fuzzy Multi-Attribute Decision Making (FUZZY MADM). Yogyakarta: Graha Ilmu. 
[12] Open Group. (2009). The Open Group Architecture Framework:Architecture Development Method. Dipetik 2014, dari http://pubs.opengroup.org/architecture/togaf9-doc/arch/

[13] Pratiwi, N. P. (2013). Perancangan business Architecuture and technology architecuture Untuk sistem informasi akademik pada Telkom University dengan berbasis framework togaf ADM. Bandung: Fakultas Rekayasa Industri, Universitas Telkom.

[14] SuaraPembaruan. (2007, Agustus 30). Suara Pembaharuan. Dipetik Februari 18, 2014, dari http://www.suarapembaruan.com/News/2007/08/30/Utama/ut02.htm

[15] Sugiyono, P. D. (2012). Metode Penelitian Kombinasi (Mixed Methods). Bandung: Alfabeta CV.

[16] Targowski, A. S. (2003). Electronic Enterprise:Strategy and Architecture. Western Michigan University, USA.

[17] University, T. (t.thn.). Profil Telkom University. (Telkom University) Dipetik 01 13, 2015, dari Telkom University: http://www.telkomuniversity.ac.id/index.php/page/profile

[18] Varveris L., H. K. (2005). Building Enterprise Architecture with TOGAF: An Introduction to Using the Framework, Method, and System Architect. Telelogic White Paper Version 1.

[19] Vielba, F. V. (2006). Reducing the M\&A Risks, The Role of IT in Mergers and Acquisitions. Palgrave Macmillan.

[20] Weill, P., \& Ross, J. (2004). IT Governance, How Top Performers Manage IT Decision Rights for Superior Results. Boston, Massachusetts: Harvard Business School Press.

[21] VANIYA, Nilesh. 2011. Building Preparedness for Mergers and Acquisitions - The role of Enterprise Architecture Practice. School of Information and Communication Technology Griffith University, Australia 
